IZA DP No. 9180

Susceptibility to Default Training Options Across the Population

Lex Borghans

Bart H.H. Golsteyn

July 2015 


\title{
Susceptibility to Default Training Options Across the Population
}

\author{
Lex Borghans \\ Maastricht University (ROA) \\ and IZA \\ Bart H.H. Golsteyn \\ Maastricht University (ROA), \\ SOFI and IZA
}

Discussion Paper No. 9180

July 2015

IZA

P.O. Box 7240

53072 Bonn

Germany

Phone: +49-228-3894-0

Fax: +49-228-3894-180

E-mail: iza@iza.org

Any opinions expressed here are those of the author(s) and not those of IZA. Research published in this series may include views on policy, but the institute itself takes no institutional policy positions. The IZA research network is committed to the IZA Guiding Principles of Research Integrity.

The Institute for the Study of Labor (IZA) in Bonn is a local and virtual international research center and a place of communication between science, politics and business. IZA is an independent nonprofit organization supported by Deutsche Post Foundation. The center is associated with the University of Bonn and offers a stimulating research environment through its international network, workshops and conferences, data service, project support, research visits and doctoral program. IZA engages in (i) original and internationally competitive research in all fields of labor economics, (ii) development of policy concepts, and (iii) dissemination of research results and concepts to the interested public.

IZA Discussion Papers often represent preliminary work and are circulated to encourage discussion. Citation of such a paper should account for its provisional character. A revised version may be available directly from the author. 


\section{ABSTRACT}

\section{Susceptibility to Default Training Options Across the Population*}

This paper analyzes the tendency of people to choose default options when offered courses to acquire job related skills. We ask a random sample of Dutch people aged 6-80 which three skills are most important in their (future or past) jobs. Further on in the survey, we randomly select one of the skills the respondent indicated and (hypothetically) offer the respondent a course regarding this skill. The respondent can accept this offer, but can also exchange it for a course regarding one of the two other skills indicated. Our findings indicate that people generally have a strong tendency to choose the default option. This effect is similar across gender and education level. It appears that the effect of the default option is less strong around age 30 and declines after age 60.

JEL Classification: J24, J31, 12

Keywords: default option, human capital, training, experiment

Corresponding author:

Bart H.H. Golsteyn

Department of Economics

Maastricht University

P.O. Box 616

$6200 \mathrm{MD}$, Maastricht

The Netherlands

E-mail: b.golsteyn@maastrichtuniversity.nl

\footnotetext{
* We thank the editor and two anonymous referees, Daron Acemoglu, Arnaud Dupuy, Andries de Grip, Annemarie Künn-Nelen, Stephen Machin, Hessel Oosterbeek, Arthur van Soest, Anders Stenberg, Bas ter Weel, and participants at the 2007 SOLE meeting in Chicago and the 2008 EALE meeting in Amsterdam for helpful discussions. The data used in this paper are available on request. Golsteyn thanks the Volkswagen Stiftung for financial support.
} 


\section{Introduction}

Default options have been shown to strongly affect behavior in numerous contexts. ${ }^{1}$ It is plausible that defaults also matter for decisions related to human capital but the evidence collected on this relationship is thin. ${ }^{2}$ One important and unanswered question in this field is to what extent different groups of people in society are susceptible to default options.

In this paper, we analyze the effects of defaults on the choice of a course. We ask a random sample of Dutch people aged 6 through 80, which three skills are most important in the jobs they have or - for people who are not working - the jobs they would like to have. Further on in the survey, we randomly select one of the skills the respondent indicated and (hypothetically) offer the respondent a course in this skill. The respondent can accept this offer, but is also allowed to exchange it for a course regarding one of the two other skills indicated. The approach allows us to distinguish people who choose the suggested (default) courses from those picking courses from the menu.

We estimate course selection behavior using conditional logit regressions. Our estimates suggest that people on average have a strong propensity to choose the default course. The effect is similar across gender and education level. It appears that the effect of the default option is less strong around age 30 and declines after age 60 .

\footnotetext{
${ }^{1}$ Johnson and Goldstein (2003) and Abadie and Gay (2006) show for instance that the amount of organ donors is much lower in countries where people by default are not an organ donor compared to countries where people by default are organ donors. Other studies have shown that defaults matter with respect to car insurances (Johnson et al. 1993), car purchases (Park et al. 2000), consent with e-mail marketing (Johnson et al. 2002), and pensions with 401(k) saving (Carroll et al. 2009). Altmann and Falk (2014) report that cooperative defaults increase contributions to a public good.

${ }^{2}$ Borghans and Golsteyn (2014) show that defaults affect the choices people make regarding training decisions of recent graduates. Research often focuses on young people. However, theory predicts that the effects might change across age. The period in which people can reap the benefits of their investments changes across time and people become more mature as they age. Our first contribution relative to this paper is that we study the question in a representative sample. The second contribution is that we let people choose the skills themselves instead of offering them the choice between various skills. This implies that the courses that are offered to them later on are more in line with their true interests.
} 
The remainder of this paper is organized as follows. In section 2 we describe the design of the experiment, and provide some descriptive data. Section 3 contains our empirical approach. Section 4 presents the main findings. Section 5 concludes.

\section{Design of the experiment}

Our experiment is included in the Life Long Learning Survey. This survey is a supplement of the Dutch National Bank Household Survey (DNB Household Survey), which is a representative panel of Dutch households. Participants answer questions over the Internet. ${ }^{3}$ Annually there is a basic questionnaire which is split up into seven subquestionnaires that are distributed in different weeks of the year. In other weeks, supplements can be sent to the participants of the panel.

An advantage of the DNB Household Survey is that within households, both adults and children (from 6 years of age onwards) participate. The use of internet allows randomization and wordings of questions which depend on earlier answers of the respondents. In total 2,445 people participated in the experiment. Table 1 shows that approximately half of the sample is male, and that the participants are on average around 43 years of age. $17 \%$ of the sample is still in school (including students), half of the sample is working, around $15 \%$ is retired, and $20 \%$ is occupied with a different activity (unemployed, housewife, disabled, else). In order to investigate whether the sample is representative, we compare these statistics with those of the DNB Household Survey. Part b of Table 1 reveals that most of the statistics are similar in the original sample and the sample we use. The average age is remarkably similar in the subgroups in both

\footnotetext{
${ }^{3}$ It is unlikely that there is selective non-response because of a lack of having a computer or internet access. People who do not have a computer or internet access receive a (simple) computer through CenER data.
} 
samples. In our sample, there are more retired women and fewer students than in the original sample.

-- Table 1a, b --

In the experiment, people will make a choice for a training course from a set of courses relevant for their work or potential work. To this aim, we have to determine the relevant skills of the respondents' occupation or potential occupation, and offer them a choice from a set of courses. We will describe these elements of the design step by step.

\section{The relevant skills for the participants}

We want the courses offered in the experiment to be relevant for the current or a potential occupation. Since important skills can be very different for each occupation we asked the respondents themselves to indicate the most important skills of their work. Questions in this experiment refer to a specific occupation while the sample consists of people with a job, but also of adults who are not participating and children who are still in school. Therefore, an approach was needed to focus the respondents on a specific occupation. For those who are working, this is their current job. The question we asked is:

Can you name three skills that according to you are the most important to do your work successfully (e.g. specific skills, computer skills, working with people, endurance, physical condition)? 
Respondents could state three skills that were recorded as string variables. ${ }^{4}$

For people who are currently not participating we adjusted the question as

\section{follows:}

Can you name three skills that are according to you, if you would start to work, the most important to do your work successfully (e.g. specific skills, computer skills, working with people, endurance, physical condition)?

We also included retired workers in our survey. We asked them:

Can you name three skills that are according to you the most important to do the work you used to have successfully (e.g. specific skills, computer skills, working with people, endurance, physical condition)?

People at school, aged 16 and older were asked:

Can you name three skills that are according to you, when you start to work later on, the most important to do your work successfully (e.g. knowledge of regulations, computer skills, working with people, endurance, physical condition)?

\footnotetext{
${ }^{4}$ Note that it is not feasible to give an overview of these skills since they are different for each respondent. Every respondent entered three skills. It was not possible to continue the survey if one entered less than three skills. A handful of respondents entered "I don't know" instead of a skill or mentioned the same skill more than once. We excluded these respondents. Although the wording varies, dealing with people (about 14\%), job specific skills (about 10\%), communication (about 9\%), accuracy (about 7\%), and dealing with stress (about 6\%) are often mentioned.
} 
For children younger than 16 we first asked the question:

What do you want to become when you grow up?

in order to get them focused on a specific occupation, and then we asked:

Which three things do you think are most important for you by the time you are working? For instance, being good at arithmetic, language, working with other people.

Scope to learn

We investigate in one of the analyses to what extent people choose courses from which they can learn and whether the respondents tend to choose courses from which they can learn if these are offered by default. To this aim, we ask:

Can you indicate for each aspect how much you can still learn?

The answers range from 1 nothing to 5 very much. Figure $1 \mathrm{~A}$ in the appendix shows that the mean answer to the question decreases both for men and women with age as expected. 


\section{Offer of a course}

At the end of the survey people receive a hypothetical offer of a course. To avoid that people try to answer in a socially desirable or consistent way, the questions about the skills that are important in the job and this hypothetical offer have been separated as much as possible in the survey.

The offer for adults who are employed was phrased in the following way:

Suppose your job has a new settlement in which everyone during working hours can follow a course $<\mathrm{X}>$ at the expense of the employer, adapted to the level of the individual participant. It is however also possible to switch courses for a course $<\mathrm{Y}>$ or a course $<\mathrm{Z}>$.

in which $\langle\mathrm{X}>,<\mathrm{Y}>$ and $\langle\mathrm{Z}>$ are the three skills that have been mentioned earlier on in the survey by the respondent. Hence, a skill mentioned by the respondent translates directly into a course (e.g. if the respondent mentioned "programming in Stata", then the course will be "programming in Stata"). The order of these three skills is randomized, so $<\mathrm{X}>,<\mathrm{Y}>$, and $<\mathrm{Z}>$ might have a different order than 1,2 , and 3. For people who are at school "your job" is replaced by “your school”, and rather than "course” we used a "project week." For people without work (including retired people) the "municipality" rather than the employer was making this offer.

Following this question, respondents could indicate first whether they would take $<\mathrm{X}>$, or preferred to switch to another course. If they choose another course, the choice 
between $<\mathrm{Y}>$ and $<\mathrm{Z}>$ was offered to them. This design of the question thereby creates a clear default option.

\section{Empirical approach}

We are interested in estimating the effect of the default on the probability that a course is chosen, and especially whether this effect varies across the population. We investigate this by analyzing within individual whether the course which was offered by default had a higher probability to be chosen than the two other courses which were offered to the individual. We estimate the following conditional logit model:

$\ln \frac{p_{i c}}{1-p_{i c}}=\alpha_{0} D_{i c}+\alpha_{1} X_{i c}+\alpha_{2} D_{i c} * Z_{i}+\alpha_{3} C_{c}+v_{i}+\varepsilon_{i c}$, with $i=1, \ldots, \mathrm{N}$ and $c=2,3$.

In this model, $p$ presents the probability that individual $i$ chooses course $c . D$ is a dummy variable indicating that individual $i$ was offered course $c$ as a default option. $X$ presents characteristics of the course. $Z$ is a vector of individual characteristics. Because we estimate this model with individual fixed effects, we do not include $Z$ as a separate predictor. Instead, we analyze the interaction between $Z$ and $D$, which reveals the characteristics of people who are more likely to choose a course that is offered by default. $C$ is a vector of dummies for the original order of the courses, excluding one course as a reference category. These dummies will pick up average differences in preferences between courses. $v$ is the individual fixed effect, $\varepsilon$ is the error term.

The individual characteristics $Z$ included in the model are: gender, educational attainment, social status, and age. We investigate whether the effect of the default differs 
across age, both for the full sample and separately by individual characteristics. ${ }^{5}$ To investigate the variation in the default effect by age, we repeatedly estimate the model separately for age groups, with a moving window of 5 years. To investigate how this effect differs by individual characteristics, (in the tables and the graphs) we estimate separate models for each individual characteristic (e.g. we estimate the model separately for men and for women) and (in the tables) we additionally estimate a model for the full sample with interactions of the default effect with individual characteristics.

We also investigate reasons for people to choose the course. In the model, this is represented by $X$. The respondents indicated for each skill how much they think they can still learn regarding the skill. ${ }^{6}$ We explore whether people who indicate that they can learn more from the course are also more likely to choose the default.

\section{Results}

Table 2 presents the results of the conditional logit regression. In the first column, the estimates are presented for the full sample. The results indicate that the second and the third skill are chosen less frequently than the first skill. Courses offered as a default option have a 1.8 times higher probability to be chosen than courses that were not offered by default. ${ }^{7}$

\footnotetext{
${ }^{5}$ We will describe the results as age effects. Obviously, these effects may however also reveal cohort effects. With our data it is not possible to identify whether the effects are age or cohort effects.

${ }^{6}$ The answers on the question are measured on a 5 point Likert scale. In our analyses, we standardize these answers to mean zero and standard deviation one.

${ }^{7}$ In the experiment, we first ask people to state three skills they consider important. Then we randomize these skills and make a course offer. In the first stage it might be that people mention important skills first. In order to investigate this, we analyzed whether the effect of the default differs between the skills mentioned $1^{\text {st }}, 2^{\text {nd }}$ or $3^{\text {rd }}$ and find no differences. It is important to note that respondents probably do not consider the courses to be of equal importance. We will show in a later analysis in this paper that they can for instance learn more from some courses than from others. It is therefore not the case that they choose the default because all courses are of equal value to them.
} 
The second and third columns show the separate results for men and women. Although women appear somewhat more likely to choose the default, column four indicates that the effect of the default does not differ significantly between men and women. The table shows that these results remain robust when we limit the sample to working individuals.

-- Table 2 --

Table 3 shows the default effect by educational levels. The default effects of the highest two tertiary levels of education appear smaller than the effects of the other levels, although the differences are not (or only marginally) significant. The effects for working individuals are similar to those of the full sample.

-- Table 3 --

Figure 1a shows the variation in the default parameter across age with a moving window of 5 years. The graph reveals that slightly above 30 and after age 60, people are less inclined to choose the default. The lower tendency to choose the default slightly above age 30 is similar in the group of working individuals. The decreasing inclination to choose the default after age 60 cannot be observed for working individuals as people start retiring at that age.

-- Figure 1a, $1 \mathrm{~b}$-- 
Figure 2 and 3 show respectively that the patterns are similar for men and women and for people with high and low educational backgrounds. There are some differences. The lower inclination to select the default slightly after age 30 observed in the full sample seems to a larger extent due to women than men. A similar pattern appears when we limit the sample to working individuals only. The lower tendency to select the default after age 60 is driven more by men than by women. Slightly before age 30 and age 60 lower educated people are more likely to select the default than higher educated individuals.

-- Figure 2a, b and 3a, b--

In table 4 the scope to learn from the course is included in the model. People who can learn more from a course select that course more often. The results show that courses, which train skills with a high scope to learn, are chosen independently of the default. The coefficient on the interaction of the default and the scope to learn is very small. This can be interpreted as good news: individuals choose training in a way to encounter their (selfrated) shortage in a specific skill even if this training is not suggested as default. The effects for working individuals are similar to those of the full sample. This finding is novel relative to the results of Borghans and Golsteyn (2014) who report for a sample of young graduates that the ability to learn from a course positively affects the probability to choose the default. ${ }^{8}$ Apparently, this tendency is not the same for individuals across the life cycle.

\footnotetext{
${ }^{8}$ Altmann, Falk and Grunewald (2013) explain that default effects are more pronounced if the interests of the default setter and the decision maker are more closely aligned.
} 
-- Table 4 --

\section{Sensitivity checks}

One question is whether the changes in the default parameter across age are driven by changes in the activities people are involved in. The first six columns in table 5 show that the point estimates are similar and the estimates are not significantly different between working individuals and children, students and other non-working individuals. However, retired individuals are significantly less likely to choose the default than working people. ${ }^{9}$ This may indicate that retired people are less likely to choose the default or that retired people have understood the question differently compared to other people. Importantly, retired people are typically also older than the other individuals so in the last column we control for a set of age groups. This column indicates that the effect of the default is similar (i.e. the interaction effects are close to unity) for working people, retired people, children, students and other non-workers. We conclude from this that the answers of workers, children, students, non-workers and retired people seem to be comparable, i.e. the interpretation of the questions in the experiment does not differ between those who have jobs and those who answer the questions with hypothetical jobs in mind. However, it is not possible to fully rule out that the groups have interpreted the question differently. Therefore, we show all results separately for the main group in the sample: working individuals only.

\footnotetext{
${ }^{9}$ Note that the results are displayed as odds ratios which implies that if a coefficient is smaller than 1 , the effect is negative.
} 
Another question is to what extent our experiment with hypothetical courses can be informative for a setting in which people choose real courses. In order to investigate this properly, our results would have to be tested in the field. The closest we can get to arguing whether our results also hold in a real setting is by asking people after they chose the course:

How large do you estimate the chance to be that you would participate in the chosen course if you had to spend one evening a week for half a year?"10

The answers to this question may serve as an indication of the extent to which a person would choose the course in a real setting. Table 6 reveals that people who are more serious about participating in the course in reality are marginally more likely to choose the default option. This implies that our experiment with hypothetical choices seems to be informative about choice patterns in real settings. If anything, our setting appears to show a lower bound of the real effect of the default. ${ }^{11}$ For working respondents there are no statistically significant interactions between the default and true participation in the course.

\footnotetext{
${ }^{10}$ The answer categories are: 1. Very unlikely, 2. A small chance, 3. 50-50, 4. A large chance, 5. Certainly or almost certainly. We standardize these answers to a mean of zero and a standard deviation of one in our analysis.

${ }^{11}$ Some participants may choose the default because they are indifferent between the courses. If anything this attenuates our results since our sensitivity analysis shows that the results are stronger for those who are more serious about following the course if it would be a real offer.
} 
-- Table 6 --

\section{Conclusions}

This paper analyzes to what extent default options affect the choice of a course, and how this effect varies across gender, educational level and age. In a survey, Dutch people across ages 6-80 are (hypothetically) offered a default course with two alternatives. Our findings indicate that people generally have a strong tendency to choose the default option. This effect is similar across gender and education level. It appears that the effect of the default option is less strong around age 30 and declines after age 60 .

In the literature on libertarian paternalism, it is suggested that defaults (or nudges) can substantially influence people's behavior while still giving them the opportunity to make a choice. In our paper, managers could set default training options in order to guide people's choices while giving them also the option to freely choose courses themselves. There is an important critique on this idea: the nudge stimulates people to choose an option desired by the default setter. This behavior does not have to be in the interest of the individual subject to the nudge or to society. Hence, as pointed out by critics of libertarian paternalism, defaults may lead to better or worse choices depending on the benevolence of the default setter. 


\section{References}

Abadie A., S. Gay (2006), “The impact of presumed consent legislation on cadaveric organ donation: a cross country study.” Journal of Health Economics 25(4), pp. 599-620.

Altmann, S., A. Falk (2014), “The impact of cooperation defaults on voluntary contributions to public goods”, mimeo University of Bonn.

Altmann, S., A. Falk, A. Grunewald (2013), “Incentives and information as driving forces of default effects.” IZA Discussion Paper No. 7610.

Borghans, L., B. Golsteyn (2014), “Default options and training participation.” Empirical Economics 46(4), 1417-1428.

Carroll G., J. Choi, D. Laibson, B. Madrian, A. Metrick (2009), “Optimal defaults and active decisions.” Quarterly Journal of Economics 124(4), pp. 1639-1674.

Johnson, E., D. Goldstein (2003), “Do defaults save lives?” Science 302, pp. 1338-1339.

Johnson E., J. Hershey, J. Meszaros, H. Kunreuther (1993), “framing, probability distortions, and insurance decisions.” Journal of Risk and Uncertainty 7(1), pp. $35-53$.

Johnson E., S. Bellman, G. Lohnse (2002), “Defaults, framing and privacy: why opting in-opting out.” Marketing Letters 13(1), pp. 5-15.

Park, C., S. Yun, D. MacInnis (2000), “Choosing what I want versus rejecting what I do not want: an application of decision framing to product option choice decisions.” Journal of Marketing Research 37, pp. 187-202. 
Table 1a

Characteristics of the Life Long Learning sample

\begin{tabular}{lrrr}
\hline & $\%$ & $\begin{array}{r}\text { mean } \\
\text { age }\end{array}$ & $\begin{array}{r}\% \\
\text { male }\end{array}$ \\
\hline Men & 47.9 & 41.0 & \\
Women & 52.1 & 45.4 & \\
Working & 48.8 & 42.6 & 58.9 \\
Retired & 15.0 & 69.6 & 75.4 \\
At School & 16.6 & 13.6 & 48.3 \\
Others not working & 19.6 & 50.2 & 20.7 \\
\hline
\end{tabular}

Note: Students are included in the group “at school.” Source: Life Long Learning Survey, 2004

Table 1b

Characteristics of the DNB Household sample

\begin{tabular}{lcrr}
\hline & $\%$ & $\begin{array}{r}\text { mean } \\
\text { age }\end{array}$ & $\begin{array}{r}\% \\
\text { male }\end{array}$ \\
\hline Men & 51.0 & 40.6 & \\
Women & 49.0 & 40.0 & \\
Working & 47.8 & 42.0 & 58.1 \\
Retired & 11.4 & 69.9 & 68.4 \\
At School & 22.8 & 13.8 & 51.7 \\
Others not working & 18.1 & 50.8 & 20.1 \\
\hline
\end{tabular}

Note: Students are included in the group “at school.” Source: DNB Household Survey, 2004 
Table 2

The effect of the default on the choice of a course

\begin{tabular}{lccccc}
\hline & $(1)$ & $\begin{array}{c}(2) \\
\text { Women }\end{array}$ & $\begin{array}{c}(3) \\
\text { Men }\end{array}$ & $\begin{array}{c}(4) \\
\text { All }\end{array}$ & $\begin{array}{c}\text { Working } \\
\text { individuals }\end{array}$ \\
\hline Default & $1.87^{* * *}$ & $1.93^{* * *}$ & $1.81^{* * *}$ & $1.93^{* * *}$ & $1.92^{* * *}$ \\
& $(15.30)$ & $(11.16)$ & $(10.49)$ & $(11.19)$ & $(7.11)$ \\
Default*male & & & & 0.93 & 1.07 \\
& & & & $(-0.84)$ & $(0.56)$ \\
Second skill & $0.79^{* * *}$ & $0.80^{* * *}$ & $0.78^{* * *}$ & $0.79^{* * *}$ & $0.79^{* * *}$ \\
& $(-4.69)$ & $(-3.02)$ & $(-3.61)$ & $(-4.70)$ & $(-3.37)$ \\
Third skill & $0.72^{* * *}$ & $0.73^{* * *}$ & $0.72^{* * *}$ & $0.72^{* * *}$ & $0.64^{* * *}$ \\
& $(-6.39)$ & $(-4.34)$ & $(-4.72)$ & $(-6.41)$ & $(-6.02)$ \\
Observations & & & & & \\
Groups & 7,335 & 3,504 & 3,831 & 7,335 & 3,573 \\
\hline
\end{tabular}

Note: Each column shows the result of a conditional logit model. The model reveals within person to what extent an independent variable changes the odds to choose the course. The reported coefficients are odds ratios, i.e. the exponent of the coefficient (so a zero coefficient implies an odds ratio of 1). Second and third skill are dummy variables of the skills mentioned by the respondent. Z-statistics in parentheses, *** $\mathrm{p}<0.01,{ }^{* *} \mathrm{p}<0.05,{ }^{*} \mathrm{p}<0.1$. Source: Life Long Learning Survey, 2004. 
Table 3

The effect of the default on the choice of a course, by educational level

\begin{tabular}{|c|c|c|c|c|c|}
\hline & $\begin{array}{c}\text { (1) } \\
\text { Level } 1\end{array}$ & $\begin{array}{c}(2) \\
\text { Level } 2\end{array}$ & $\begin{array}{c}\text { (3) } \\
\text { Level } 3\end{array}$ & $\begin{array}{l}(4) \\
\text { All }\end{array}$ & $\begin{array}{c}\text { (5) } \\
\text { Working } \\
\text { individuals }\end{array}$ \\
\hline Default & $\begin{array}{c}2.01 * * * \\
(8.95)\end{array}$ & $\begin{array}{c}1.92 * * * \\
(8.55)\end{array}$ & $\begin{array}{c}1.67 * * * \\
(7.07)\end{array}$ & $\begin{array}{c}2.01 * * * \\
(10.75)\end{array}$ & $\begin{array}{c}2.29 * * * \\
(6.63)\end{array}$ \\
\hline Default*Level 2 & & & & $\begin{array}{c}0.94 \\
(-0.58)\end{array}$ & $\begin{array}{c}0.97 \\
(-0.18)\end{array}$ \\
\hline Default*Level 3 & & & & $\begin{array}{c}0.83^{*} \\
(-1.92)\end{array}$ & $\begin{array}{c}0.75 * \\
(-1.90)\end{array}$ \\
\hline Second skill & $\begin{array}{l}0.79 * * \\
(-2.46)\end{array}$ & $\begin{array}{c}0.71 * * * \\
(-3.69)\end{array}$ & $\begin{array}{c}0.94 \\
(-0.71)\end{array}$ & $\begin{array}{c}0.79 * * * \\
(-4.70)\end{array}$ & $\begin{array}{c}0.79 * * * \\
(-3.38)\end{array}$ \\
\hline Third skill & $\begin{array}{c}0.71 * * * \\
(-3.50)\end{array}$ & $\begin{array}{c}0.68 * * * \\
(-4.12)\end{array}$ & $\begin{array}{c}0.76 * * * \\
(-3.03)\end{array}$ & $\begin{array}{c}0.72 * * * \\
(-6.41)\end{array}$ & $\begin{array}{c}0.63 * * * \\
(-6.06)\end{array}$ \\
\hline Observations & 2,007 & 2,136 & 2,334 & 7,335 & 3,573 \\
\hline Groups & 669 & 712 & 778 & 2445 & 1191 \\
\hline
\end{tabular}

Note: Each column shows the result of a conditional logit model. The model reveals within person to what extent an independent variable changes the odds to choose the course. The reported coefficients are odds ratios, i.e. the exponent of the coefficient (so a zero coefficient implies an odds ratio of 1). Level 1 is primary education and VMBO (the lowest level of secondary school); Level 2 is HAVO/VWO (the two higher levels of secondary school) and MBO (the lowest level of tertiary education; Level 3 is HBO and WO (the two highest levels of tertiary education. Second and third skill are dummy variables of the skills mentioned by the respondent. Z-statistics in parentheses, ${ }^{* * *} \mathrm{p}<0.01,{ }^{* *} \mathrm{p}<0.05,{ }^{*} \mathrm{p}<0.1$. Source: Life Long Learning Survey, 2004. 
Figure 1a

The effect of the default on the choice of a course across age

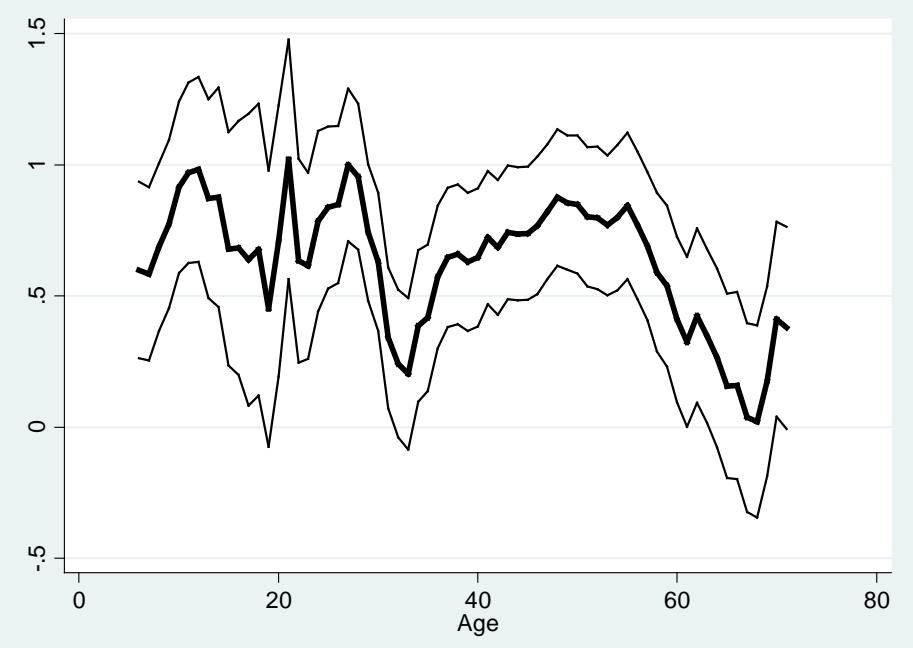

Figure $1 \mathrm{~b}$

The effect of the default on the choice of a course across age, working individuals only

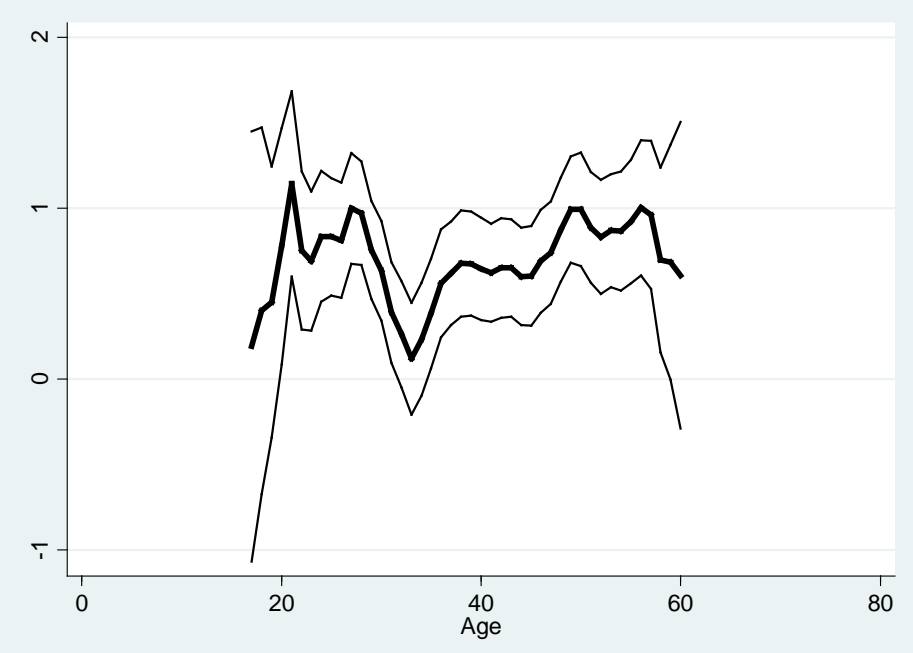

Note: The figures report the coefficients of the default variable in conditional logit regressions with the choice of a course as the dependent variable and as independent variables: the default, and dummies for skill two and three. The model is estimated repeatedly with a moving window of 5 years. In panel (a) the model is estimated for the full sample. Panel (b) shows the results for working individuals only. 95\% confidence interval bounds are reported as well. Source: Life Long Learning Survey, 2004. 
Figure 2a

The effect of the default on the choice of a course across age, by gender

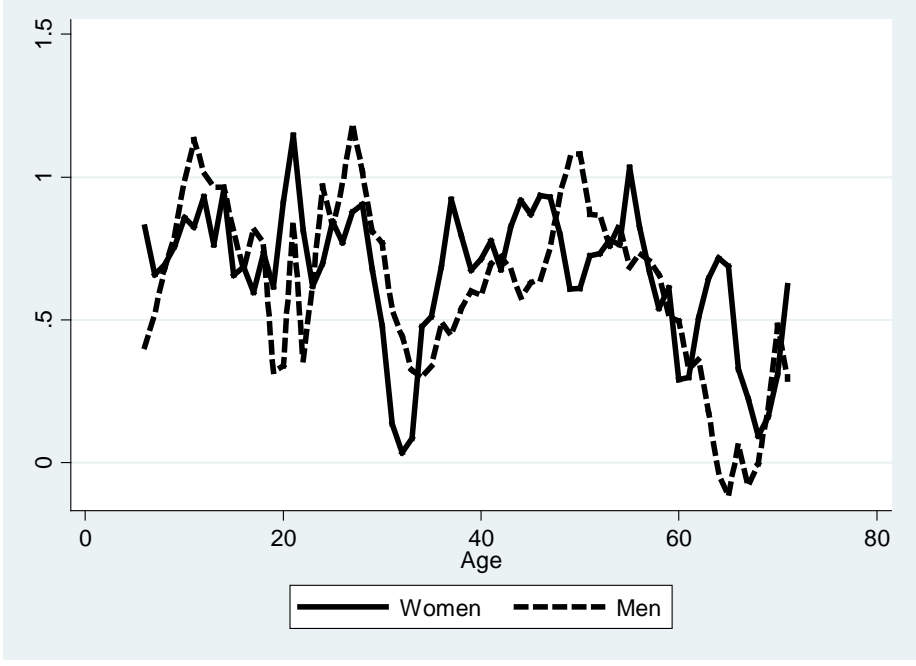

Figure $2 b$

The effect of the default on the choice of a course across age, by gender, working individuals only

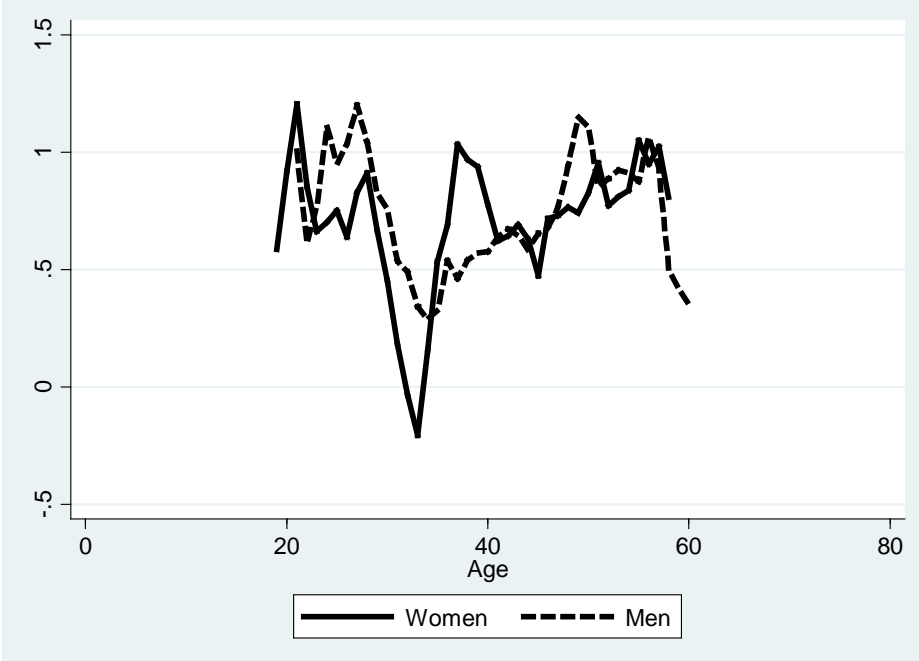

Note: The figures report the coefficients of the default variable in two sets of conditional logit regressions (one for men and one for women) with the choice of a course as the dependent variable and as independent variables: the default, and dummies for skill two and three. The model is estimated repeatedly with a moving window of 5 years. In panel (a) the model is estimated for the full sample. Panel (b) shows the results for working individuals only. Source: Life Long Learning Survey, 2004. 
Figure 3a

The effect of the default on the choice of a course across age by educational level

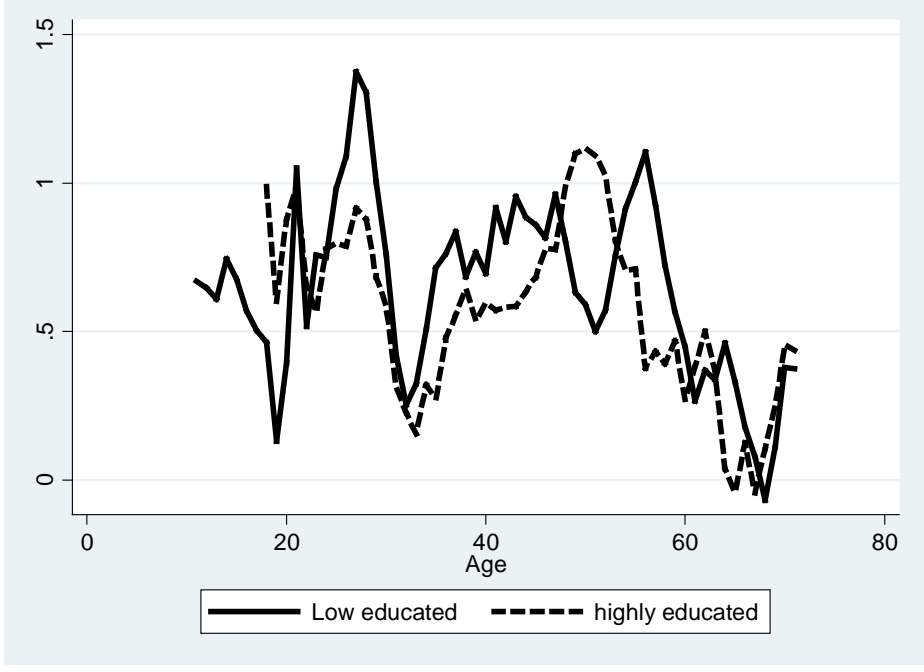

Figure 3b

The effect of the default on the choice of a course across age by educational level, for working individuals

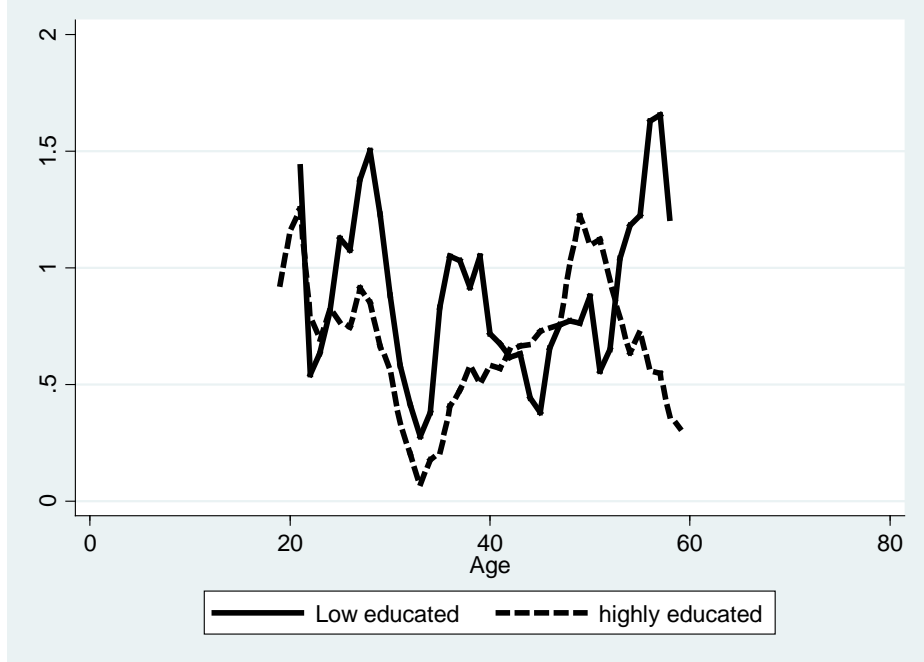

The figures report the coefficients of the default variable in two sets of conditional logit (one for low educated (primary education, secondary education levels) and one for highly educated (tertiary education levels)) with the choice of a course as the dependent variable and as independent variables: the default, and dummies for skill two and three. The model is estimated repeatedly with a moving window of 5 years. In panel (a) the model is estimated for the full sample. Panel (b) shows the results for working individuals only. Source: Life Long Learning Survey, 2004. 
Table 4

Default and scope to learn from the course

\begin{tabular}{ccccccc}
\hline & & Full sample & \multicolumn{3}{c}{ Working individuals } \\
& $(1)$ & $(2)$ & $(3)$ & $(1)$ & $(2)$ & $(3)$ \\
& All & Women & Men & All & Women & Men \\
\hline \multirow{2}{*}{ Default } & & & & & & \\
& $1.96^{* * *}$ & $2.06^{* * *}$ & $1.89^{* * *}$ & $2.30^{* * *}$ & $2.18^{* * *}$ & $2.38^{* * *}$ \\
& $(15.59)$ & $(11.30)$ & $(10.71)$ & $(12.48)$ & $(7.45)$ & $(9.97)$ \\
Learn & $2.06^{* * *}$ & $2.07^{* * *}$ & $2.07 * * *$ & $3.04^{* * *}$ & $2.91^{* * *}$ & $3.15^{* * *}$ \\
& $(15.23)$ & $(10.40)$ & $(11.15)$ & $(13.79)$ & $(8.75)$ & $(10.66)$ \\
Default*learn & $1.09^{*}$ & 1.06 & 1.11 & 0.99 & 1.02 & 0.97 \\
& $(1.77)$ & $(0.75)$ & $(1.57)$ & $(-0.10)$ & $(0.18)$ & $(-0.26)$ \\
Second skill & $0.81^{* * *}$ & $0.82^{* * *}$ & $0.80^{* * *}$ & $0.86^{* *}$ & 0.88 & $0.83^{*}$ \\
& $(-4.14)$ & $(-2.64)$ & $(-3.20)$ & $(-2.06)$ & $(-1.04)$ & $(-1.83)$ \\
Third skill & $0.76^{* * *}$ & $0.77^{* * *}$ & $0.76^{* * *}$ & $0.72^{* * *}$ & $0.79^{*}$ & $0.68^{* * *}$ \\
& $(-5.09)$ & $(-3.41)$ & $(-3.80)$ & $(-4.04)$ & $(-1.86)$ & $(-3.70)$ \\
& & & & & & \\
Observations & 7,335 & 3,504 & 3,831 & 3,573 & 1,467 & 2,106 \\
Groups & 2445 & 1168 & 1277 & 1191 & 489 & 702 \\
\hline
\end{tabular}

Note: Each column shows the result of a conditional logit model. The model reveals within person to what extent an independent variable changes the odds to choose the course. The reported coefficients are odds ratios, i.e. the exponent of the coefficient (so a zero coefficient implies an odds ratio of 1 ). The answer categories to the question on ability to learn from the course is standardized to mean zero and standard deviation one. Second and third skill are dummy variables of the skills mentioned by the respondent. Zstatistics in parentheses, ${ }^{* * *} \mathrm{p}<0.01,{ }^{* *} \mathrm{p}<0.05,{ }^{*} \mathrm{p}<0.1$. Source: Life Long Learning Survey, 2004. 
Table 5

The effect of the default on the choice of a course, by social activity

\begin{tabular}{|c|c|c|c|c|c|c|c|}
\hline & $\begin{array}{c}\text { (1) } \\
\text { Working }\end{array}$ & $\begin{array}{c}\text { (2) } \\
\text { Retired }\end{array}$ & $\begin{array}{c}\text { (3) } \\
\text { Student }\end{array}$ & $\begin{array}{l}4) \\
\text { Child }\end{array}$ & $\begin{array}{c}\text { (5) } \\
\text { Other non- } \\
\text { working }\end{array}$ & $\begin{array}{l}\text { (6) } \\
\text { All }\end{array}$ & $\begin{array}{l}\text { (7) } \\
\text { All }\end{array}$ \\
\hline Default & $\begin{array}{l}1.99 * * * \\
(11.75)\end{array}$ & $\begin{array}{c}1.32 * * * \\
(2.62)\end{array}$ & $\begin{array}{c}1.90 * * * \\
(3.32)\end{array}$ & $\begin{array}{c}2.07 * * * \\
(6.01)\end{array}$ & $\begin{array}{c}1.96 * * * \\
(7.32)\end{array}$ & $\begin{array}{l}1.99 * * * \\
(11.77)\end{array}$ & $\begin{array}{l}1.53^{*} \\
(1.87)\end{array}$ \\
\hline Default*retired & & & & & & $\begin{array}{c}0.67 * * * \\
(-3.23)\end{array}$ & $\begin{array}{c}0.81 \\
(-1.01)\end{array}$ \\
\hline Default*student & & & & & & $\begin{array}{c}0.92 \\
(-0.46)\end{array}$ & $\begin{array}{c}0.83 \\
(-0.59)\end{array}$ \\
\hline Default*child & & & & & & $\begin{array}{l}1.02 \\
(0.17)\end{array}$ & $\begin{array}{c}0.99 \\
(-0.01)\end{array}$ \\
\hline Default*non-working & & & & & & $\begin{array}{c}0.99 \\
(-0.11)\end{array}$ & $\begin{array}{l}1.01 \\
(0.10)\end{array}$ \\
\hline Second skill & $\begin{array}{c}0.79 * * * \\
(-3.36)\end{array}$ & $\begin{array}{l}1.08 \\
(0.60)\end{array}$ & $\begin{array}{c}0.49 * * * \\
(-3.01)\end{array}$ & $\begin{array}{c}0.64 * * * \\
(-2.97)\end{array}$ & $\begin{array}{l}0.78 * * \\
(-2.17)\end{array}$ & $\begin{array}{c}0.79 * * * \\
(-4.77)\end{array}$ & $\begin{array}{c}0.79 * * * \\
(-4.83)\end{array}$ \\
\hline Third skill & $\begin{array}{c}0.64 * * * \\
(-6.03)\end{array}$ & $\begin{array}{c}1.09 \\
(0.70)\end{array}$ & $\begin{array}{l}0.57 * * \\
(-2.50)\end{array}$ & $\begin{array}{c}0.75^{*} \\
(-1.92)\end{array}$ & $\begin{array}{c}0.74 * * * \\
(-2.65)\end{array}$ & $\begin{array}{c}0.72 * * * \\
(-6.32)\end{array}$ & $\begin{array}{c}0.72 * * * \\
(-6.39)\end{array}$ \\
\hline $\begin{array}{l}\text { Set of age groups } \\
\text { included }\end{array}$ & No & No & No & No & No & No & Yes \\
\hline Observations & 3,573 & 1,107 & 369 & 852 & 1,434 & 7,335 & 7,335 \\
\hline Groups & 1,191 & 369 & 123 & 284 & 478 & 2,445 & 2,445 \\
\hline
\end{tabular}

Note: Each column shows the result of a conditional logit model. The model reveals within person to what extent an independent variable changes the odds to choose the course. The reported coefficients are odds ratios, i.e. the exponent of the coefficient (so a zero coefficient implies an odds ratio of 1). Second and third skill are dummy variables of the skills mentioned by the respondent. Z-statistics in parentheses, *** $\mathrm{p}<0.01,{ }^{* *} \mathrm{p}<0.05,{ }^{*} \mathrm{p}<0.1$. Source: Life Long Learning Survey, 2004. 
Table 6

Default and the intention to participate in the chosen course

\begin{tabular}{|c|c|c|c|c|c|c|}
\hline & \multicolumn{3}{|c|}{ Full sample } & \multicolumn{3}{|c|}{ Working individuals } \\
\hline & (1) & (2) & (3) & (1) & (2) & (3) \\
\hline & All & Women & Men & All & Women & Men \\
\hline \multirow[t]{2}{*}{ Default } & $1.84^{* * *}$ & $1.89 * * *$ & $1.81^{* * *}$ & $1.99 * * *$ & $1.94^{* * *}$ & $2.04^{* * *}$ \\
\hline & (13.71) & $(9.76)$ & (9.64) & (11.73) & (7.18) & $(9.32)$ \\
\hline \multirow[t]{2}{*}{ Default*Participate } & $1.09 *$ & 1.05 & $1.12^{*}$ & 1.00 & 0.86 & 1.09 \\
\hline & $(1.92)$ & $(0.73)$ & (1.91) & $(-0.07)$ & $(-1.44)$ & $(1.05)$ \\
\hline \multirow[t]{2}{*}{ Second skill } & $0.84^{* * *}$ & $0.84^{* *}$ & $0.84 * *$ & $0.79 * * *$ & $0.80^{* *}$ & $0.78^{* * *}$ \\
\hline & $(-3.29)$ & $(-2.25)$ & $(-2.38)$ & $(-3.36)$ & $(-2.01)$ & $(-2.73)$ \\
\hline \multirow[t]{2}{*}{ Third skill } & $0.73^{* * *}$ & $0.74 * * *$ & $0.72 * * *$ & $0.64 * * *$ & $0.66^{* * *}$ & $0.62^{* * *}$ \\
\hline & $(-5.65)$ & $(-3.76)$ & $(-4.21)$ & $(-6.03)$ & $(-3.64)$ & $(-4.86)$ \\
\hline Observations & 6,114 & 2,874 & 3,240 & 3,573 & 1,467 & 2,106 \\
\hline Groups & 2038 & 958 & 1080 & 1191 & 489 & 702 \\
\hline
\end{tabular}

Note: Each column shows the result of a conditional logit model. The model reveals within person to what extent an independent variable changes the odds to choose the course. The reported coefficients are odds ratios, i.e. the exponent of the coefficient (so a zero coefficient implies an odds ratio of 1). "Participate" is the answer to the question "How large do you estimate the chance to be that you would participate in the chosen course if it would take one night a week for half a year?” Answer categories are: 1. Very unlikely, 2. A small chance, 3. 50-50, 4. A large chance, 5. Certainly or almost certainly. These answer categories are standardized to mean zero and standard deviation one. Second and third skill are dummy variables of the skills mentioned by the respondent. Z-statistics in parentheses, ${ }^{* * *} \mathrm{p}<0.01,{ }^{* *} \mathrm{p}<0.05,{ }^{*} \mathrm{p}<0.1$. Source: Life Long Learning Survey, 2004. 
Appendix

Figure $1 \mathrm{~A}$

Scope to learn from a course across age, for men and women

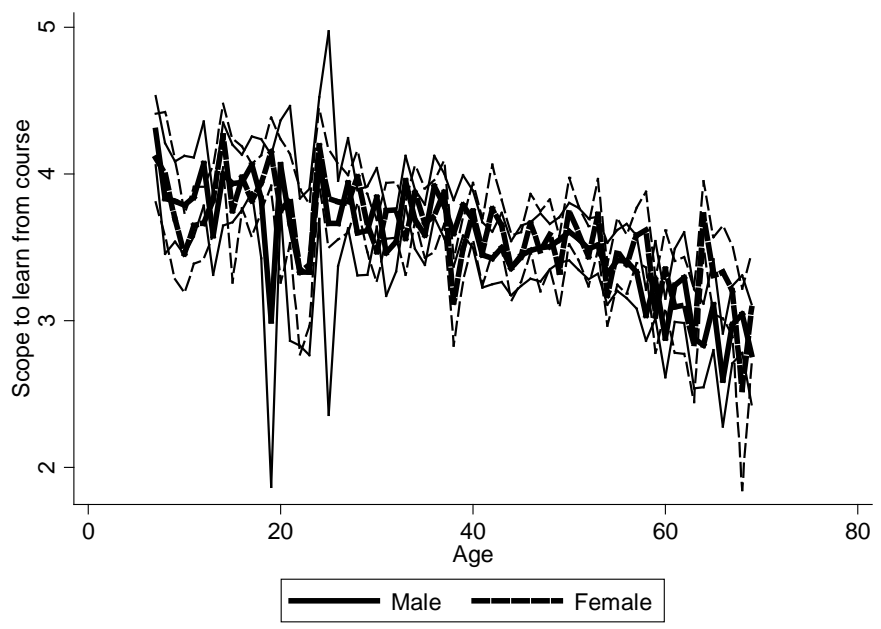

Note: the figure displays the mean answer on the question "Can you indicate for each aspect how much you can still learn?”(the answers range from 1 nothing to 5 very much) for each age (separately for men and women). 95\% confidence intervals are also displayed. 